\title{
Perancangan Alat Bantu Angkat Brush Seal Welding Fixture dengan Metode Reba dan Qfd
}

\author{
Sri Zetli, Heru Kusbiantoro \\ Jurusan Teknik Industri Universitas Putera Batam \\ E-mail: zetli.sri@gmail.com
}

\begin{abstract}
Loading and unloading are the processes which are perform at before and after welding process. On this processes, there is a fixture-lifting activity from assembly table move to the Welding machine. The lifting activity as well is perform at after welding process; to uninstall the fixture from the machine then move it to assembly table. This process is performed by 2 persons, because the fixture is quiet heavy, $50 \mathrm{Kg}$ with 40 Inches in diameter and 2.5 inches in the thickness. However, the distance from assembly table to the welding machine is $300 \mathrm{~cm}$. approximately. By this condition, based on The Rapid Entire Body Assesment (REBA) Analysis is resulted Final Score 9 and categorized as a High Risk Level Process. As well based on the scoring of Nordic Body Map (NBM) shows result that there is a high potential pain on the nape, shoulders, arms, back, waist and calves, hence than this activity is consider as Not Ergonomic Process for the worker.Based on the condition as describe above, survey been conducted with Quality Function Deployment (QFD) approach, which concluded that the loading and unloading process is need a lifting tool or equipment to lift up and move the welding fixture. For this purposes to eliminate this difficulty, proposed to have a Lifting Equipment Design could be a trolley or a lifter.
\end{abstract}

Keywords: $N B M, R E B A, Q F D$

\begin{abstract}
Abstrak
Proses loading dan unloading adalah suatu proses yang dilakukan pada saat sebelum dan sesudah proses welding dilakukan. Pada proses ini terjadi aktivitas pengangkatan fixture welding dari meja assembly dibawa ke mesin dan dipasang pada mesin welding. Kemudian setelah proses welding selesai, fixture dilepas kembali dan dibawa ke meja assembly. Proses ini dilakukan oleh dua orang pekerja, karena fixture cukup berat, yaitu sekitar $52 \mathrm{Kg}$, dengan diameter $40 \mathrm{inchi}$, dan tebal 2.5 inchi, sedangkan jarak dari meja assembly ke mesin sekitar $300 \mathrm{~cm}$. Berdasarkan penilaian Rapid Entire Body Assesment (REBA) didapatkan nilai skor akhir 9, dan digolongkan sebagai process dengan level resiko tinggi. Kemudian berdasarkan penilaian pada kuisioner Nordic Body Map (NBM) menunjukkan potensi timbulnya rasa sakit pada bagian tengkuk, bahu, lengan, punggung, pinggang dan betis, sehingga aktivitas ini kurang ergonomi bagi pekerja. Dari paparan kondisi diatas, kemudian diadakan survey dengan pendekatan quality function deployment (QFD), bahwasanya dibutuhkan alat bantu angkat untuk mengangkat fixture welding pada saat proses loading dan unloading. Untuk hal itu diusulkan perancangan sebuah alat bantu angkat berupa trolley atau lifter yang bisa menghilangkan kesulitan dan keluhan pekerja.
\end{abstract}

Kata kunci: NBM, REBA, QFD

\section{Pendahuluan}

Perkembangan industri modern bisa diartikan sebagai perubahan dari industri kuno yang masih banyak menggunakan cara-cara tradisional dalam melakukan proses poduksi beralih pada cara-cara baru yang lebih mengedepankan teknologi dari penemuan-penemuan yang sangat berguna bagi kelangsungan hidup manusia. Artinya industri kuno bukanlah sesuatu yang di pandang tidak layak,tetapi dengan adanya industri kuno ini yang akhirnya banyak mendasari penemuanpenemuan dan diterapkan pada industri modern. Ergonomi adalah salah satu ilmu yang mempelajari tentang bagaimana merancanga dan mengembangkan produk dengan memperhatikan peningkatan kesehatan, keselamatan dan juga produktivitas kerja perlu diperhatikan untuk 
mendapatkan mutu terbaik dari produk yang dihasilkan. Melalui penyesuaian mesin, alat dan perlengkapan kerja terhadap tenaga kerja yang dapat mendukung kemudahan, kenyamanan dan efisiensi kerja [3].

Dalam penelitian yang berlatar belakang dari konsep ergonomi yaitu lebih tepatnya pada proses loading dan unloading. Dimana pada saat melakukan proses ini ada pemindahan welding fixture dari meja assembly lalu dibawa ke mesin welding untuk selanjutnya dilakukan proses welding. Setelah welding selesai, fixture dilakukan secara manual. Artinya pada saat memindahkan fixture tersebut dilakukan oleh pekerja tanpa alat bantu angkat dan harus dilakukan oleh dua orang pekerja. Karena disamping ukurannya yang besar juga bebannya yang sudah melebihi batasan manusia apabila dilakukan satu pekerja. Sehingga memerlukan bantuan pada saat melakukan pemindahan, hal ini juga berisiko terjadinya kecelakaan kerja pada saat melakukan pemindahan. Disamping kesulitan ini juga adanya keluhan yang dialami oleh pekerja yang biasa melakukan proses ini. Karena beban dan juga ukuran dari fixture yang cukup besar. Berat fixture sekitar $52 \mathrm{Kg}$ dengan diameter 40 inchi dan tebal 2,5 inchi serta jarak meja assembly ke mesin sekitar 3 Meter.

Dari penelitian ini bertujuan untuk mengetahui seberapa besar tingkat kesulitan dan keluhan pada saat proses loading dan unloading dengan metode REBA serta bagaimanakah usulan desain perancangan alat bantu angkat yang tepat untuk proses loading dan unloading dengan pendekatan QFD dengan estiamsi biaya yang diperlukan

\section{Methodologi}

Metodelogi penelitian merupakan langkahlangkah yang dilakukan dalam melaksanakan sebuah penelitian. Adapun langkah-langkah dalam penelitian ini dapat dilihat pada desain penelitian pada gambar 1 .

\subsection{Studi Lapangan}

Langkah - langakah dalam desain penelitian yaitu diawali dengan studi lapangan terdiri dari observasi dan wawancara. Observasi proses yaitu melihat serta mengamati proses yang akan kita jadikan sebagai bahan penelitian dengan fokus pada pokok bahasan yaitu proses pemindahan brush seal welding fixture dari meja assembly ke mesin secara manual. Dan juga menarik gambaran yang bisa dijadikan landasan berpikir dalam pengembangan ide selanjutnya. Sedangkan wawancara dengan pekerja yang melakukan proses pemindahan brush seal welding fixture dengan tujuan menggali keterangan-keterangan yang bisa di jadikan masukan dalam penelitian. Sehingga sangatlah penting bagi peneliti dan pekerja agar terwujudnya tujuan dari penelitian yang akan di capai.

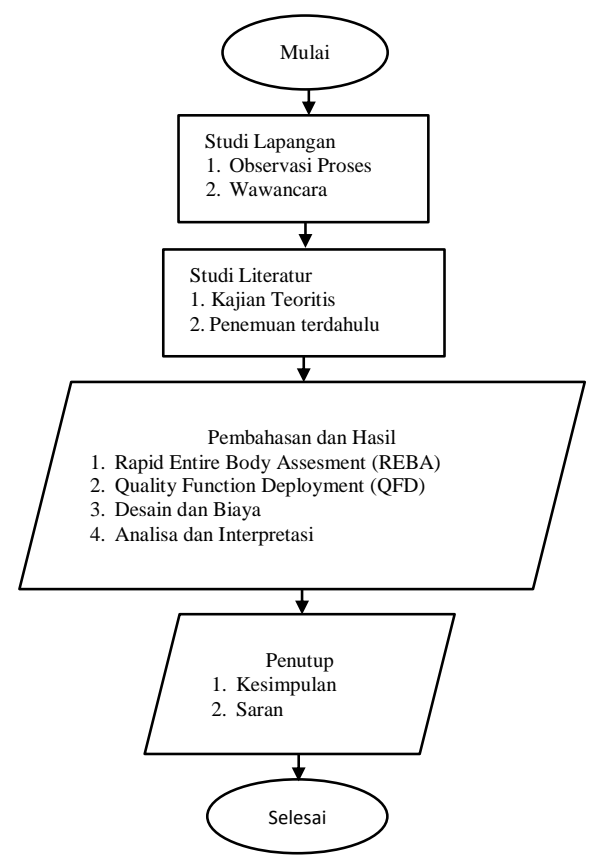

Gambar 1. Desain Penelitian

\subsection{Studi Literatur}

Langkah berikutnya yaitu dengan studi literatur terdiri dari kajian teoritis dan penelitian terdahulu. Dalam kajian teoritis ini penulis mengambil landasan dari buku-buku dan jurnaljurnal yang berhubungan dengan penelitian saat ini. Dan dengan mengambil manfaat dari penelitian - penelitian terdahulu sebagai referensi untuk mendapatkan ide-ide atau konsep - konsep untuk dijadikan tambahan sebagai landasan berpikir dalam menyelesaikan penelitian ini.

\subsection{Pengumpulan Data}

Pada tahap pengumpulan data meliputi rekam aktivitas (foto) dan penyebaran kuesioner. Pada tahap rekam aktivitas (foto) ini penulis akan mengambil atau merekam gambar dengan kamera untuk mendapatkan foto pada saat proses kerja sedang berlangsung dan menganalisa dengan metode REBA. Metode Rapid Entire Body Assessment (REBA) pertama kali dikembangkan oleh Sue Hignett dan Lynn McAtamney dan diterbitkan dalam jurnal Applied ergonomic tahun 2000 [7]. Metode REBA relatif mudah digunakan, karena untuk mengetahui nilai suatu anggota tubuh tidak diperlukan besar sudut yang spesifik, namun 
hanya berupa range sudut. Pada akhirnya nilai akhir dari metode REBA memberikan indikasi level resiko dari suatu pekerjaan dan tindakan yang harus dilakukan atau diambil tindakan. Dalam [6] terdapat empat tahapan proses perhitungan yang dilalui yaitu:

1. Mengumpulkan data mengenai postur pekerja pada saat melakukan aktivitas dengan menggunakan video atau foto.

2. Menentukan sudut dari postur tubuh saat bekerja padabagian yang ada score nilainya seperti, Badan (Trunk), Leher (Neck), Kaki (Leg), Lengan bagian atas (Upper arm), Lengan bagian bawah (Lower arm) dan Pergelangan tangan (Hand Wrist).

3. Menentukan berat beban, pegangan (coupling) dan aktivitas kerja.

4. Menentukan nilai REBA untuk postur yang relevan dan menghitung skor akhir dari aktivitas yang dilakukan.

Adapun tujuan yaitu untuk menentukan sudut-sudut yang akan di ambil, selanjutnya dipakai untuk memperoleh skor REBA pada aktivitas pekerja. Sedangkan pada bagian penyebaran kuesioner penulis membuat angket atau kuisioner yang akan diisi oleh pekerja yang melakukan proses pemindahan brush seal welding fixture. Adapun tujuan yang ingin dicapai penulis adalah mendapatkan data yang akurat untuk melengkapi persyaratan pada metode yang di ambil. Pada kuisioner pertama yaitu akan meminta responden untuk mengisi tabel Nordic Body Map (NBM) sesuai dengan keluhan yang dialami pekerja dengan memberikan tanda silang. NBM adalaha salah satu alat ukur ergonomi sederhana yang dapat digunakan untuk mengenali sumber penyebab keluhan musculoskeletal adalah Nordic Body Map menurut Corlet (1992) dalam [7] menyatakan bahwa melalui Nordic Body Map dapat diketahui bagian-bagian otot yang mengalami keluhan mulai dari rasa tidak nyaman sampai sangat sakit. Selanjutnya mengisi tabel masukkan dengan memberikan masukkan keinginan atau kebutuhan pada kolom masukkan pekerja dengan mempertimbangkan tingkat kepentingan perlunya alat bantu angkat yang akan di usulkan.

\subsection{Pembahasan dan Hasil}

Pada tahap pembahasan dan hasil dilakukan Assesment awal postur kerja dengan metode REBA selanjutnya pembobotan dengan QFD. QFD adalah suatu cara yang digunakan untuk meningkatkan kualitas barang atau jasa dengan memahami kebutuhan konsumen kemudian menghubungkannya dengan karakteristik teknis untuk menghasilkan suatu barang atau jasa pada setiap tahap pembuatan barang atau jasa yang dihasilkan (Rosnani Ginting, 2010) dalam [1]. QFD sering digunakan untuk membantu bisnis memusatkan perhatian pada kebutuhan para pelanggan ketika menyusun spesifikasi desain dan fabrikasi. Dalam [4] secara ringkas mendefinisikan QFD sebagai metode terstruktur yang digunakan dalam proses perencanaan dan pengembangan produk untuk menetapkan spesifikasi kebutuhan dan keinginan konsumen serta mengevaluasi suatu produk dalam memenuhi kebutuhan dan keinginan konsumen. Kemudian dalam menyusun QFD sendiri ada beberapa teknik atau metode untuk mendapatkan data primer yang nantinya digunakan untuk menyusun kebutuhan konsumen atau pengguna alat atau produk tersebut [2], yaitu dengan cara menyebarkan kuesioner dan observasi.

QFD dibagi menjadi empat fase yang digunakan untuk menghubungkan kebutuhan konsumen dengan karakteristik perancangan produk, dan kemudian menerjemahkannya ke dalam karakteristik part, operasi manufaktur, dan karakteristik produksi. Kemudian pada tahap identifikasi kebutuhan konsumen, dan karakteristik part metode QFD diaplikasikan pada tahap perancangan produk. Tujuan utama dari QFD adalah menentukan prioritas kriteria rancangan yang menjadi fokus utama dalam perancangan dan pengembangan produk [1].

Pada tahap ini penentuan skor pembobotan didapatkan dari data kuisioner keluhan pekerja (voice customer) dengan memperhatikan hubungan sebab akibat dan juga menterjemahkan kebutuhan dan keinginan pekerja yang biasa melakukan proses ini. Pendekatan Quality Function Deployment (QFD) adalah sebuah metodologi untuk mempresentasikan kebutuhan dan keinginan konsumen ke dalam suatu produk yang memiliki persyaratan teknis dan karakteristik dengan membuat diagram House Of Quality (HOQ) secara berurutan [5]. Kemudian memberikan nilai skor dari tingkat kepentingan berupa user importance dan technical importance serta technical priority yang akan di gambarkan dalam design perancangan.

Pembahasan dan hasil dalam tahap ini menghasilkan design perancangan yang bisa memenuhi keinginan konsumen dengan memenuhi gagasan atau ide dari user importance, technical respon dan technical priority. Dalam tahap ini ada beberapa langkah, pertama akan dilakukan pemodelan hasil perancangan dengan gambar 3D juga perhitungan estimasi biaya yang dibutuhkan untuk pembuatan alat bantu angkat dengan bantuan pihak ketiga, dalam hal ini vendor 
atau general supplier yang biasa membuat peralatan fabrikasi untuk perusahaan. Kedua dilakukan analisa dari design perancangan dengan menjelaskan sistem kerja dari alat tersebut dan juga kapasitas dari perancangan apabila digunakan dalam membantu proses loading dan unloading. Kemudian juga biaya yang dibutuhkan untuk membuat alat bantu angkat dari desain yang diusulkan. Sehingga akan mudah pada saat diusulkan.

\subsection{Penutup}

Pada tahap akhir ini akan membahas simpulan dari hasil design perancangan dengan memperhatikan tujuan yang ingin dicapai dari penelitian dan kemudian memberikan saran ataupun masukkan untuk perbaikan dari design perancangan yang selanjutnya akan di usulkan.

\section{Hasil dan Pembahasan}

\subsection{Hasil}

\subsubsection{Pengumpulan Data}

Pada tahapan pengumpulan data terdapat beberapa langkah yang di peroleh dari proses kerja pada saat melakukan aktivitas pengangkatan brush seal welding fixture, proses ini disebut dengan proses loading dan unloading. Adapun proses kerja pada welding brush seal sebagai berikut :

1. Preparation yaitu persiapan pekerjaan yang sudah didistribusikan pada production berupa material sesuai work order, fixture dan tools (peralatan) yang terlihat pada gambar 2 .

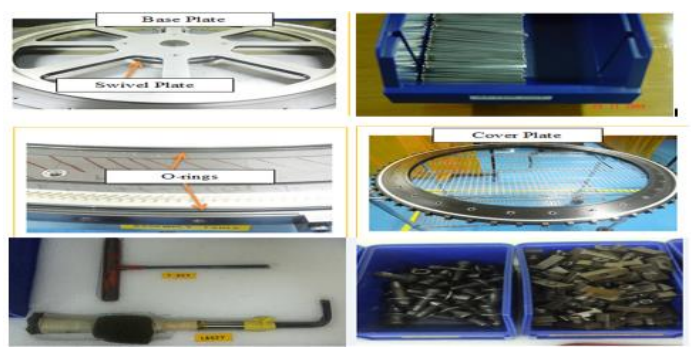

Gambar 2. Materials, Fixture dan Tools

2. Assembly yaitu proses penyusunan material pada fixture dengan mengikuti prosedur pada work instruction. Material di susun pada base plate dan kemudian di pasang cover plate dan selanjutnya di ikat dengan screw dan di kuatkan dengan L-key . Dan terakhir di pasang pegangan atau handel untuk mengangkat fixture seperti pada gambar 3 .

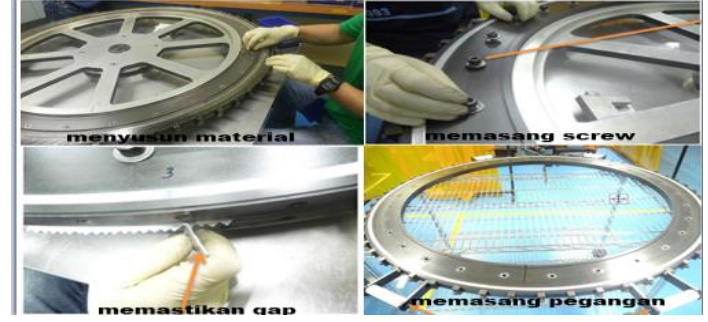

Gambar 3. Proses Assembly

3. Loading yaitu proses dimana fixture yang sudah siap di pindahkan dan di pasang ke mesin welding oleh dua orang yaitu teknisi dan operator. Pada saat melakukan proses pemindahan ini nantinya akan kita jadikan obyek penelitian, karena adanya beban dan juga dilakukan secara manual. Sehingga aktivitas ini kurang ergonomi, terlihat pada gambar 4 .

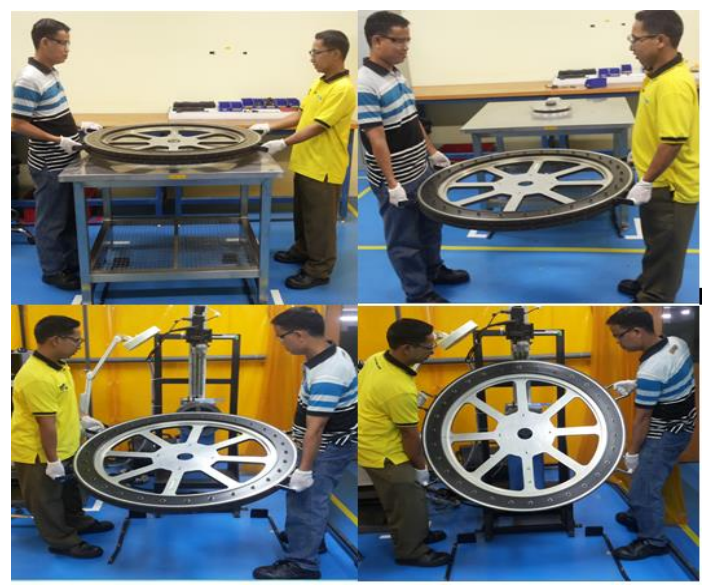

Gambar 4. Proses Loading

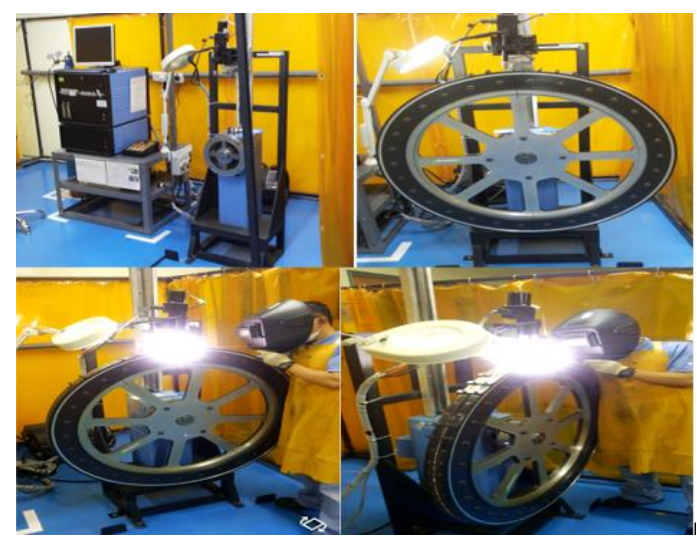

Gambar 5. Proses Welding

4. Welding yaitu proses dimana fixture sudah terpasang pada mesin dan selanjutnya teknisi melakukan proses setting parameter dan dilanjutkan dengan welding, seperti pada gambar 5 . 
5. Unloading yaitu proses kebalikan dari loading, yaitu melepas fixture dari mesin dan kemudian memindahkan lagi ke posisi semula atau diatas meja assembly.

6. Disassembly yaitu proses melepaskan cover plate dari base plate dengan peralatan yang sama pada saat digunakan assembly proses. Pada proses diassembly ini tidak terlalu lama atau sulit, berbeda dengan proses pada saat assembly.

7. Finish yaitu proses terakhir untuk teknisi melakukan pekerjaan welding. Pada saat proses finishing ini teknisi melakukan inspection pada hasil weldingan dengan mengunakan caliper dan nogono jig sebelum di submit ke bagian Quality Control (QC), terlihat pada gambar 6.

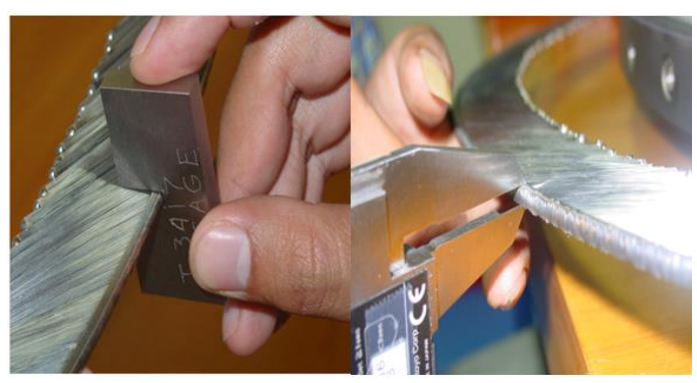

Gambar 6. Proses Inspection

\subsubsection{Penyebaran Kuisioner}

Kuisioner diambil dari pekerja yang melakukan proses ini yaitu empat orang pekerja ditambah satu orang dari proses enginer untuk mendapatkan tambahan masukkan yang nantinya digunakan untuk kebutuhan desain perancangan. Kuisioner yang diambil adalah kuisioner Nordic Body Map yang berupa pertanyaan mengenai segmen bagian tubuh yang mengalami keluhan dan masukkan pekerja atau Voice of Customer (VOC) untuk kebutuhan perancangan desain alat bantu angkat untuk membuat House Of Quality dari metode Quality Function Deployment (QFD). Tabel 1 adalah hasil dari kuisioner yang diakumulasi dan dijadikan tabel.

Dari tabel 1 terdapat 12 segmen tubuh yang mengalami keluhan sakit yang di alami pekerja. Hasil kuisioner yang sudah di akumulasi ini di ambil dari lima responden yang kemudian dijadikan bahan pertimbangan untuk perlunya memperbaiki sistem kerja. Sehingga dari proses ini diusulkan menggunaan alat bantu angkat agar tidak ada keluhan pekerja dan pekerja akan merasakan kenyamanan pada saat bekerja.
Tabel 1.

Hasil kuisioner Nordic Body Map (NBM)

\begin{tabular}{|c|c|c|}
\hline No & Jenis Keluhan & $\begin{array}{c}\text { Rata- } \\
\text { rata }(\%)\end{array}$ \\
\hline 0 & Sakit kaku pada bagian leher atas & 50 \\
\hline 1 & Sakit kaku pada bagian tengkuk & 75 \\
\hline 2 & Sakit di bahu kiri & 70 \\
\hline 3 & Sakit di bahu kanan & 70 \\
\hline 4 & Sakit lengan atas kiri & 75 \\
\hline 5 & Sakit di punggung & 65 \\
\hline 6 & Sakit lengan atas kanan & 75 \\
\hline 7 & Sakit pada pinggang & 65 \\
\hline 8 & Sakit pada pinggul & 45 \\
\hline 9 & Sakit pada pantat & 0 \\
\hline 10 & Sakit pada siku kiri & 0 \\
\hline 11 & Sakit pada siku kanan & 0 \\
\hline 12 & Sakit lengan bawah kiri & 75 \\
\hline 13 & Sakit lengan bawah kanan & 75 \\
\hline 14 & Sakit pada pergelangan tangan kiri & 35 \\
\hline 15 & Sakit pada pergelangan tangan kanan & 35 \\
\hline 16 & Sakit pada tangan kiri & 35 \\
\hline 17 & Sakit pada tangan kanan & 35 \\
\hline 18 & Sakit pada paha kiri & 15 \\
\hline 19 & Sakit pada paha kanan & 15 \\
\hline 20 & Sakit pada lutut kiri & 0 \\
\hline 21 & Sakit pada lutut kanan & 0 \\
\hline 22 & Sakit pada betis kiri & 75 \\
\hline 23 & Sakit pada betis kanan & 75 \\
\hline 24 & Sakit pada pergelangan kaki kiri & 0 \\
\hline 25 & Sakit pada pergelangan kaki kanan & 0 \\
\hline 26 & Sakit pada kaki kiri & 0 \\
\hline 27 & Sakit pada kaki kanan & 0 \\
\hline
\end{tabular}

Tabel 2.

Pernyataan kebutuhan

\begin{tabular}{|c|c|c|c|}
\hline No. & $\begin{array}{c}\text { Pernyataan Kebutuhan } \\
\text { Pekerja }\end{array}$ & Jumlah & Persentase \\
\hline 1 & $\begin{array}{l}\text { Dibutuhkan alat bantu } \\
\text { angkat untuk mengangkat } \\
\text { beban welding fixture }\end{array}$ & 5 & 100 \\
\hline 2 & $\begin{array}{l}\text { Perancangan alat bantu } \\
\text { angkat } \\
\text { menghilangkan kesulitan } \\
\text { pekerja pada } \\
\text { memindahkan saat } \\
\text { fixture }\end{array}$ & 4 & 80 \\
\hline 3 & $\begin{array}{l}\text { Desain perancangan aman } \\
\text { pada saat digunakan }\end{array}$ & 3 & 60 \\
\hline 4 & $\begin{array}{l}\text { Desain perancangan } \\
\text { praktis dan mudah dalam } \\
\text { penggunaannya }\end{array}$ & 4 & 80 \\
\hline \multirow[t]{3}{*}{5} & $\begin{array}{lcr}\begin{array}{l}\text { Desain } \\
\text { dengan }\end{array} & \text { posisa } & \text { disesuaikan } \\
\text { welding } & & \\
\end{array}$ & 4 & 80 \\
\hline & & 20 & 400 \\
\hline & & 4.00 & 80.00 \\
\hline
\end{tabular}

Selanjutnya adalah mengumpulkan dan menyederhanakan masukkan pekerja atau Voice Of Customer kedalam satu tabel pernyataan kebutuhan pekerja sebagai langkah awal untuk mebuat skor pembobotan pada House Of Quality pada pendekatan Quality Function Deployment (QFD) yang terdapat pada tabel 2. 


\subsubsection{Pengolahan Data REBA}

Pada pengolahan data ini akan dibagi menjadi 2 tahap yaitu assesment postur kerja dengan metode Rapid Entire Body Assesment REBA dan kebutuhan perancangan dengan analisa pendekatan Quality Function Deployment (QFD).

Penilaian terhadap postur kerja dengan metode REBA digunakan untuk mendapatkan gambaran yang jelas mengenai resiko yang ditimbulkan dari posisi kerja yang kurang ergonomis sehingga diketahui besaran skor dari postur kerja tersebut. Tujuan utamanya adalah untuk mengetahui level resiko yang ditimbulkan.

Tabel 3.

Perhitungan Skor REBA

No

Penilaian terhadap postur kerja di ambil dengan cara di foto pada saat pekerja melakukan aktivitas kerja, kemudian dari hasil foto tersebut diolah dengan menggunakan software solidworks untuk bisa diketahui sudut-sudut pada segmen tubuh yang dibutuhkan untuk skor REBA. Pada bagian yang diukur adalah punggung, leher, kaki, lengan atas, lengan bawah, dan pergelangan tangan yang dapat dilihat pada tabel 3 .

Perhitungan dari akhri skor REBA grup A terlihat pada tabel 4 dan grup B pada tabel 5 .
Tabel 4.

Perhitungan Skor REBA Grup A

\begin{tabular}{|c|c|c|c|c|c|c|c|c|c|c|c|c|}
\hline \multicolumn{13}{|c|}{ TABEL A } \\
\hline \multirow{4}{*}{ Badan } & \multicolumn{12}{|c|}{ Leher } \\
\hline & \multicolumn{4}{|c|}{1} & \multicolumn{4}{|c|}{2} & \multicolumn{4}{|c|}{3} \\
\hline & \multicolumn{4}{|c|}{ Kaki } & \multicolumn{4}{|c|}{ Kaki } & \multicolumn{4}{|c|}{ Kaki } \\
\hline & 1 & 2 & 3 & 4 & 1 & 2 & 3 & 4 & 1 & 2 & 3 & 4 \\
\hline 1 & 1 & 2 & 3 & 4 & 1 & 2 & 3 & 4 & 3 & 3 & 5 & 6 \\
\hline 2 & 2 & 3 & 4 & 5 & 3 & 4 & 5 & 6 & 4 & 5 & 6 & 7 \\
\hline 3 & 2 & 4 & 5 & 6 & 4 & 5 & 6 & 7 & 5 & 6 & 7 & 8 \\
\hline 4 & 3 & 5 & 6 & 7 & 5 & 6 & 7 & 8 & 6 & 7 & 8 & 9 \\
\hline 5 & 4 & 6 & 7 & 8 & 6 & 7 & 8 & 9 & 7 & 8 & 9 & 9 \\
\hline
\end{tabular}

Tabel 5.

Perhitungan Skor REBA Grup B

\begin{tabular}{|c|c|c|c|c|c|c|}
\hline \multicolumn{7}{|c|}{ TABEL B } \\
\hline \multirow{4}{*}{ Lengan } & \multicolumn{6}{|c|}{ Lengan Bawah } \\
\hline & \multicolumn{3}{|c|}{1} & \multicolumn{3}{|c|}{2} \\
\hline & \multicolumn{3}{|c|}{$\begin{array}{c}\text { Pergelangan } \\
\text { Tangan }\end{array}$} & \multicolumn{3}{|c|}{$\begin{array}{c}\text { Pergelangan } \\
\text { Tangan }\end{array}$} \\
\hline & 1 & 2 & 3 & 1 & 2 & 3 \\
\hline 1 & 1 & 2 & 2 & 1 & 2 & 3 \\
\hline 2 & 1 & 2 & 3 & 2 & 3 & 4 \\
\hline 3 & 3 & 4 & 5 & 4 & 5 & 5 \\
\hline 4 & 4 & 5 & 5 & 5 & 6 & 7 \\
\hline 5 & 6 & 7 & 8 & 7 & 8 & 8 \\
\hline
\end{tabular}

Setelah mendapatkan skor A dan B maka menentukan skor pembebanan dan skor pegangan seperti terlihat pada tabel 6 dan tabel 7 .

Tabel 6.

Perhitungan Skor Pembebanan

\begin{tabular}{cl}
\hline Skor & \multicolumn{1}{c}{ Posisi } \\
\hline+0 & Beban atau force $<5 \mathrm{~kg}$. \\
+1 & Beban atau force antara $5-10 \mathrm{~kg}$. \\
+2 & Beban atau force $>10 \mathrm{~kg}$. \\
\hline Skor & \multicolumn{1}{c}{ Posisi } \\
\hline & Pembebanan atau force secara tiba-tiba atau \\
+3 & mendadak \\
\hline
\end{tabular}

Tabel 7.

Perhitungan Skor Pegangan (Coupling)

\begin{tabular}{|c|c|}
\hline Skor & Posisi \\
\hline+0 & $\begin{array}{c}\text { Pegangan Bagus } \\
\text { Pegangan coupling baik dan kekuatan pegangan } \\
\text { berada pada posisi tengah }\end{array}$ \\
\hline+1 & $\begin{array}{c}\text { Pegangan Sedang } \\
\text { Pegangan tangan diterima, tetapi tidak ideal atau } \\
\text { pegangan optimum yang dapat diterima untuk } \\
\text { menggunakan bagian tubuh lainnya }\end{array}$ \\
\hline+2 & $\begin{array}{c}\text { Pegangan Kurang Baik } \\
\text { Pegangan ini mungkin dapat digunakan tetapi } \\
\text { tidak dapat diterima }\end{array}$ \\
\hline+3 & $\begin{array}{c}\text { Pegangan Jelek } \\
\text { Pegangan ini terlalu dipaksakan atau tidak ada } \\
\text { pegangan atau genggaman tangan, pegangan } \\
\text { bahkan tidak dapat diterima untuk menggunakan } \\
\text { bagian tubuh lainnya }\end{array}$ \\
\hline
\end{tabular}

Skor akhir dari semuanya adalah:

1. Skor $\mathrm{A}$ adalah tabel $\mathrm{A}+$ skor beban $=6+2=$ 8

2. Skor $\mathrm{B}$ adalah tabel $\mathrm{B}+$ skor pegangan $=$ $3+0=3$ 
Setelah skor A dan B didapatkan maka menentukan besarnya skor $\mathrm{C}$ dengan tabel skor $\mathrm{C}$ REBA yang terlihat pada tabel 8. Dilanjutkan dengan skor aktivitas otot pada tabel 9, sehingga perhitungan dari semua skor REBA akan kita dapatkan yaitu skor $\mathrm{C}$ di tambah dengan skor aktivitas otot $(8+1=9)$. Jadi hasil perhitungan akhir dari skor REBA adalah 9 yang terlihat pada tabel 10 level resiko.

Tabel 8.

Perhitungan Skor REBA Grup C

\begin{tabular}{c|c|c|c|c|c|c|c|c|c|c|c|c}
\hline \multicolumn{10}{c}{ Skor } & \multicolumn{10}{c|}{ TABEL C } \\
\cline { 2 - 13 } $\mathbf{A}$ & $\mathbf{1}$ & $\mathbf{2}$ & $\mathbf{3}$ & $\mathbf{4}$ & $\mathbf{5}$ & $\mathbf{6}$ & $\mathbf{7}$ & $\mathbf{8}$ & $\mathbf{9}$ & $\mathbf{1 0}$ & $\mathbf{1 1}$ & $\mathbf{1 2}$ \\
\hline $\mathbf{1}$ & 1 & 1 & 1 & 2 & 3 & 3 & 4 & 5 & 6 & 7 & 7 & 7 \\
$\mathbf{2}$ & 1 & 2 & 2 & 3 & 4 & 4 & 4 & 6 & 6 & 7 & 7 & 8 \\
$\mathbf{3}$ & 2 & 3 & 3 & 4 & 4 & 4 & 5 & 7 & 7 & 8 & 8 & 8 \\
$\mathbf{4}$ & 3 & 4 & 4 & 5 & 5 & 5 & 6 & 8 & 8 & 9 & 9 & 9 \\
$\mathbf{5}$ & 4 & 4 & 4 & 6 & 6 & 6 & 8 & 8 & 9 & 9 & 9 & 9 \\
$\mathbf{6}$ & 6 & 6 & 6 & 7 & 8 & 8 & 9 & 9 & 10 & 10 & 10 & 10 \\
$\mathbf{7}$ & 7 & 7 & 7 & 8 & 9 & 9 & 9 & 10 & 10 & 11 & 11 & 11 \\
$\mathbf{8}$ & 8 & 8 & $\mathbf{8}$ & 9 & 10 & 10 & 10 & 10 & 10 & 11 & 11 & 11 \\
$\mathbf{9}$ & 9 & 9 & 9 & 10 & 10 & 10 & 11 & 11 & 11 & 12 & 12 & 12 \\
$\mathbf{1 0}$ & 10 & 10 & 10 & 11 & 11 & 11 & 11 & 12 & 12 & 12 & 12 & 12 \\
$\mathbf{1 1}$ & 11 & 11 & 11 & 11 & 12 & 12 & 12 & 12 & 12 & 12 & 12 & 12 \\
$\mathbf{1 2}$ & 12 & 12 & 12 & 12 & 12 & 12 & 12 & 12 & 12 & 12 & 12 & 12 \\
\hline
\end{tabular}

Tabel 9.

Perhitungan Skor Aktivitas Otot

\begin{tabular}{cc}
\hline Skor & Posisi \\
\hline+1 & Satu atau lebih bagian tubuh dalam keadaan \\
& statis, misalnya ditopang untuk lebih dari 1 menit \\
$\mathbf{+ 1}$ & $\begin{array}{c}\text { Gerakan berulang-ulang terjadi, misalnya repetisi } \\
\text { lebih dari 4 kali per menit (tidak termasuk } \\
\text { berjalan) }\end{array}$ \\
& Terjadi perubahan yang signifikan pada postur \\
$\mathbf{+ 1}$ & tubuh atau postur tubuh tidak stabil selama kerja \\
\hline
\end{tabular}

Tabel 10.

Nilai Level Resiko Dan Tindakan

\begin{tabular}{|c|c|c|c|}
\hline $\begin{array}{l}\text { Skor } \\
\text { Akhir }\end{array}$ & $\begin{array}{l}\text { Tingkat } \\
\text { Resiko }\end{array}$ & $\begin{array}{c}\text { Kategori } \\
\text { Resiko }\end{array}$ & Tindakan \\
\hline 1 & 0 & $\begin{array}{l}\text { Sangat } \\
\text { Rendah }\end{array}$ & $\begin{array}{l}\text { Tidak ada tindakan } \\
\text { yang diperlukan }\end{array}$ \\
\hline $2-3$ & 1 & Rendah & $\begin{array}{l}\text { Mungkin } \\
\text { diperlukan } \\
\text { tindakan }\end{array}$ \\
\hline $4-7$ & 2 & Sedang & $\begin{array}{l}\text { Diperlukan } \\
\text { tindakan }\end{array}$ \\
\hline $8-10$ & 3 & Tinggi & $\begin{array}{l}\text { Diperlukan } \\
\text { tindakan segera }\end{array}$ \\
\hline $11-15$ & 4 & $\begin{array}{l}\text { Sangat } \\
\text { Tinggi }\end{array}$ & $\begin{array}{l}\text { Diperlukan } \\
\text { tindakan sesegera } \\
\text { mungkin }\end{array}$ \\
\hline
\end{tabular}

\subsubsection{Pengolahan Data QFD}

Langkah pada Quality Function Deployment yang pertama adalah adanya masukkan pekerja atau Voice Of Customer (VOC). Dimana masukkan yang didapatkan dengan menggunakan kuisioner dan wawancara di akomodir dari setiap respon pekerja yang melakukan proses tersebut. Kemudian data yang didapatkan diakumulasi dan diolah untuk mendapatkan skor atau pembobotan untuk membuat House Of Quality (HOQ). Data awal yang di dapat dari responden dengan melakukan pengisian kuisioner selanjutnya diolah dan diakumulasi dalam tabel 11 .

Tabel 11.

Kebutuhan Pekerja

\begin{tabular}{cl}
\hline \multicolumn{3}{c}{ Kebutuhan Pekerja } \\
\hline No. & \multicolumn{1}{c}{$\begin{array}{c}\text { Dibutuhkan alat bantu angkat untuk mengangkat } \\
\text { beban welding fixture } \\
\text { Perancangan alat bantu angkat dapat } \\
\text { menghilangkan kesulitan pekerja pada saat } \\
\text { memindahkan welding fixture }\end{array}$} \\
3 & $\begin{array}{l}\text { Desain perancangan aman pada saat digunakan } \\
\text { Desain perancangan praktis dan memudahkan }\end{array}$ \\
5 & $\begin{array}{l}\text { Desain bisa disesuaikan dengan posisi mesin } \\
\text { welding }\end{array}$ \\
\hline
\end{tabular}

Setelah mendapatkan skor dari kebutuhan pekerja langkah selanjutnya adalah menyusun technical response. Dalam menyusun technical response ini terdiri dari pekerja juga atasan, dalam hal ini diwakili oleh pihak enginering. Tujuannya adalah untuk mendapatkan ide-ide atau masukkan untuk dijadikan rumusan dalam bahan perancangan pada tabel 12 .

Tabel 12.

Technical Response

\begin{tabular}{cl}
\hline No & \multicolumn{1}{c}{ Technical Respon } \\
\hline 1 & Bisa mengangkat beban fixture \\
2 & Tidak membutuhkan tenaga extra untuk \\
3 & penggunaannya \\
4 & Bisa disesuaikan dengan ketinggian mesin \\
5 & Memakai roda pada bagian bawah \\
6 & Hanya roda bagian depan yang bisa berputar penuh \\
7 & Handel atau pegangan nyaman \\
8 & Ada pengunci pada bagian yang bisa di adjust \\
9 & Desain tidak terlalu besar dan simpel \\
10 & Bisa difungsikan sebagai meja assembly \\
\hline
\end{tabular}

Setelah menyusun technical response dilanjutkan dengan menyusun matriks hubungan dan menyusun House Of Quality. Tahapan HOQ adalah:

1. Matriks Hubungan (Matriks relationship) Matriks ini menghubungkan technical response dan customer needs, Pembobotan ini tentunya disetujui oleh semua pihak termasuk atasan. Nilai dari skor pembobotan di gambarkan dalam bentuk simbol-simbol yang nantinya di isi pada House Of Quality.

2. Membuat House Of Quality

House Of Quality dalam proses perancangan kemudian di analisa agar dapat diimplementasikan, adapun tahapan diwujudkan oleh matriks yang terdiri satu sel input (disebut 'whats') dalam $H O Q$ dan output disebut 'how' dalam $H O Q$ berikut hasil pengisian matriks berdasarkan technical requirement yaitu berisikan 
keinginan pekerja dalam perancangan alat bantu angkat brush seal welding fixture, yang ada pada tabel 12 .

Tabel 12.

Nilai House of quality (HOQ)

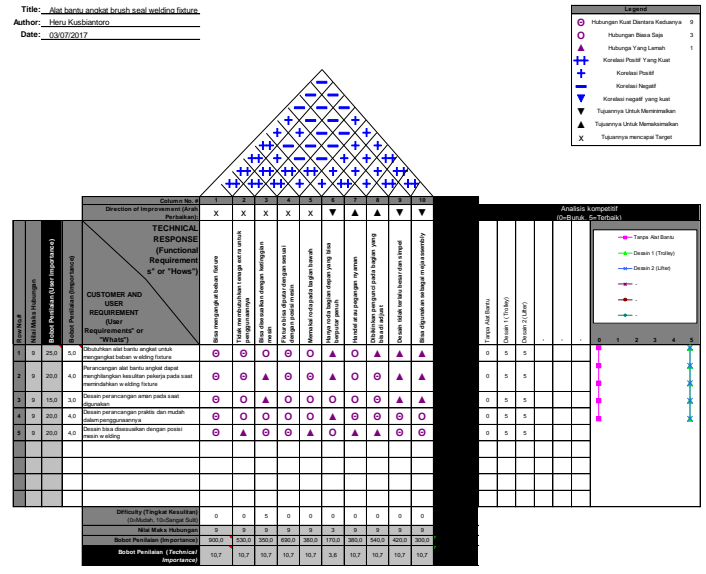

Tabel 13.

User Importance Dan Technical Importance

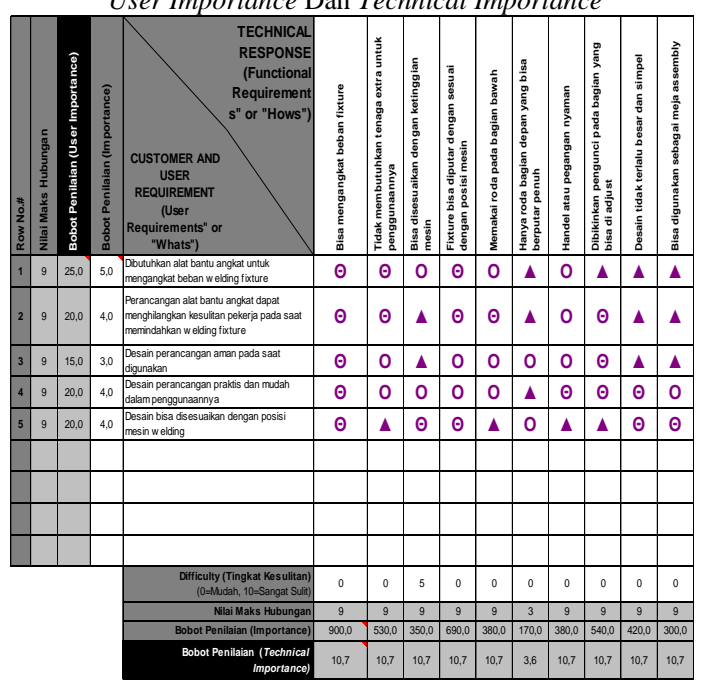

3. Menentukan User Importance Dan Technical Importance.

Penilaian ini di ambil berdasarkan relationship matriks dari bobot penilaian pada House Of Quality,kita akan melihat skor dari user importance dan technical importance untuk acuan pertimbangan pada desain perancangan alat bantu angkat brush seal welding fixture yang akan dibuat pada tabel 13.

4. Menentukan Technical Priority

Untuk menentukannya technical priority diambil dari bobot penilaian pada technical importance dan dikelompokkan, seperti pada tabel 14 .
Tabel 14.

\begin{tabular}{|c|c|c|c|c|c|}
\hline \multirow[t]{2}{*}{ No. } & \multirow[t]{2}{*}{ Technical Response } & \multirow{2}{*}{\begin{tabular}{|c|} 
Bobot \\
penilaian \\
berdasarkan \\
Technical \\
Importance
\end{tabular}} & \multirow{2}{*}{\begin{tabular}{|c} 
Prioritas \\
berdasarkan \\
Technical \\
Importance
\end{tabular}} & \multicolumn{2}{|c|}{\begin{tabular}{|c} 
Analisis Kompetitif \\
Perancangan \\
Berdasarkan \\
Pernyataan \\
Kebutuhan
\end{tabular}} \\
\hline & & & & $\begin{array}{l}\text { Design } 1 \\
\text { (Trolley) }\end{array} \mid$ & $\begin{array}{c}\text { Design 2 } \\
\text { (Lifter) }\end{array}$ \\
\hline 1 & Bisa mengangkat beban fixture & 10.7 & High Priority & v & $\mathrm{v}$ \\
\hline 2 & $\begin{array}{l}\text { Tidak membutuhkan tenaga extra } \\
\text { untuk penggunaannya }\end{array}$ & 10.7 & High Priority & $\mathrm{v}$ & v \\
\hline 3 & $\begin{array}{l}\text { Bisa disesuaikan dengan } \\
\text { ketinggian mesin } \\
\end{array}$ & 10.7 & High Priority & $\mathrm{v}$ & v \\
\hline 4 & $\begin{array}{l}\text { Fixture bisa diputar dengan } \\
\text { sesuai dengan posisi mesin }\end{array}$ & 10.7 & High Priority & v & $\mathrm{v}$ \\
\hline 5 & $\begin{array}{l}\text { Memakai roda pada bagian } \\
\text { bawah }\end{array}$ & 10.7 & High Priority & $\mathrm{v}$ & $\mathrm{v}$ \\
\hline 6 & $\begin{array}{l}\text { Hanya roda bagian depan yang } \\
\text { bisa berputar penuh }\end{array}$ & 3.6 & Low Priority & v & $\mathrm{v}$ \\
\hline 7 & Handel atau pegangan nyaman & 10.7 & High Priority & v & v \\
\hline 8 & $\begin{array}{l}\text { Dibikinkan pengunci pada bagian } \\
\text { yang bisa di adjust }\end{array}$ & 10.7 & High Priority & $\mathrm{v}$ & $\mathrm{v}$ \\
\hline 9 & $\begin{array}{l}\text { Desain tidak terlalu besar dan } \\
\text { simpel }\end{array}$ & 10.7 & High Priority & $\mathrm{v}$ & $\mathrm{v}$ \\
\hline 10 & $\begin{array}{l}\text { Bisa digunakan sebagai meja } \\
\text { assembly }\end{array}$ & 10.7 & High Priority & $\mathrm{v}$ & $\mathrm{x}$ \\
\hline
\end{tabular}

Bobot penilaian dari Technical importance skor yang masuk dalam high priority akan dijadikan acuan dalam desain perancangan dari alat antu angkat brush seal welding fixture.

\subsubsection{Perancangan Alat}

Dengan mengakomodir point-point yang sudah di berikan skor maka dari 2 usulan desain perancangan alat bantu angkat brush seal welding fixture tersebut yaitu berupa trolley dan lifter.

1. Desain Trolley

Desain ini dibuat sesuai dengan permintaan dan keinginan. Bentuk portable. Konsepnya kuat mengangkat beban fixture dengan sistem dongkrak untuk mengangkat bebannya. Dari sisi ukuran juga fix dengan fixture serta ringan pada saat digunakan. Fleksibilitas bisa di adjust sesuai keinginan dan juga mudah untuk diposisikan. Dari unsur-unsur tadi di jadikan acuan utama dalam pembutannya. Dalam penggunaanya semua memakai mekanik serta mudah dalam perawatannya. Desain trolley terlihat pada gambar 5 . 


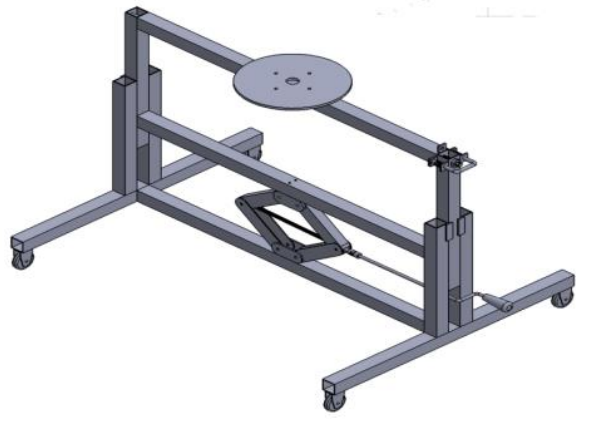

Gambar 5. Desain Trolley

\section{Desain Lifter}

Desain ini dibuat sebagai perbandingan dari desain pertama. Desain ini dibuat dengan memodifikasi produk lifter drum, kemudian di berikan hanger untuk penyangga fixture . Menggunakan sistem hidrolik untuk mengangkat beban fixture. Desain terlihat agak besar dari desain pertama yang terlihat pada gambar 6.

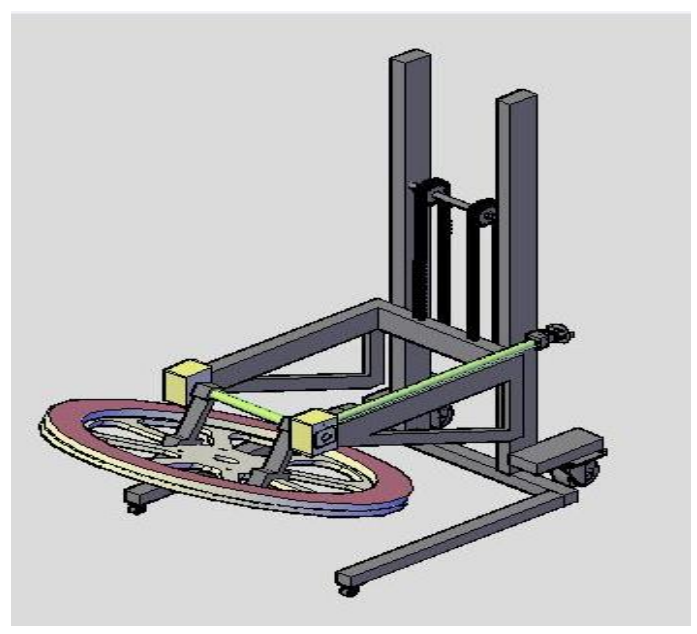

Gambar 6. Desain Lifter Tunner Modification

\subsection{Pembahasan}

Dari kedua desain yang diusulkan menggunakan konsep mekanik yang sangat mudah dalam penggunaanya, mudah dalam perawatannya. Kemudian sangat competible pada saat digunakan mengangkat beban fixture. Karena alat bantu angkat ini semua rancangannya mampu mengangkat beban lebih dari beban fixture. Desain trolley mempunyai kemampuan load capacity 1,5 ton, sedangkan lifter modification sekitar $400 \mathrm{Kg}$. Sehingga sangat mungkin sekali pekerja akan merasakan kenyamanan dan tanpa ada kesulitan dan keluhan pada saat melakukan aktivitas loading dan unloading proses welding. Dan bisa dipastikan skor Reba dari 9 bisa turunkan dan keluhan pekerja juga bisa dihilangkan. Dan desain ini sangat layak untuk diusulkan sebagai alat bantu angkat pada proses loading dan unloading. Juga kebutuhan dari pekerja akan bisa dipenuhi dengan adanya alat bantu angkat ini. Kemudian dari sisi fleksibilitas juga sangat membantu proses loading dan unloading, karena dari kedua desain ini sangat adjustable dan mudah di posisikan. Desain portable dengan roda yang bisa berputar serta memakai lock, sehingga safety pada saat beban di atas alat bantu angkat. Faktor ketinggian mesin dan juga jarak tidak akan menjadi kendala dengan adanya fleksibilitas ini. Sebelum ada penggunaan alat bantu maka proses loading dan unloading hanya bisa dilakukan oleh dua orang, tetapi apabila menggunakan alat bantu angkat proses ini nantinya akan bisa dilakukan oleh satu saja.

\section{Simpulan}

Simpulan yang dapat di ambil dari penelitian ini sebagai berikut:

1. Dari penelitian ini di ketahui besarnya keluhan dan kesulitan pada proses loading dan unloading menggunakan metode Rapid Entire Body Assesment (REBA) dengan skor akhir 9, sehingga tergolong level resiko tinggi. Sehingga diperlukan tindakan segera untuk mengurangi keluhan dan kesulitan yang di alami pekerja pada proses tersebut.

2. Penelitian ini menghasilkan usulan desain perancangan alat bantu angkat brush seal welding fixture, usulan pertama berupa trolley dan usulan kedua berupa lifter. Hasil desain perancangan ini diharapkan bisa menghilangkan kesulitan dan keluhan yang dialami pekerja melalui pendekatan quality function deployment (QFD) dengan mengakomodir ide-ide, masukkan juga gagasan yang terkumpul.

3. Dari kedua desain perancangan alat bantu angkat brush seal welding fixture ini sudah diketahui besarnya biaya dari tiap-tiap desain, sehingga akan memudahkan pada saat hasil penelitian ini yang berupa desain perancangan alat bantu angkat ini untuk diusulkan agar di jadikan bahan pertimbangan guna menghilangkan kesulitan dan keluhan yang dialami pekerja.

\section{Daftar Pustaka}

[1] Hady Widjaya, Rosnani Ginting, Aulia Ishak. Perancangan Produk Spring Bed 
Dengan Menggunakan Metode Quality Function Deployment. Jurnal Teknik Industri FT USU Vol; 2, No. 1, Mei 2014 pp. 30-34: 2.

[2] Kesuma, Angga. Perancangan Mesin Pemotong Kerupuk Labu Kuning Semi Otomatis Dengan Metode Zero One. Jurnal Mahasiswa Teknik Industri. Vol 1 (1): 1-13.

[3] Nurmianto, Eko. Ergonomi konsep dasar dan aplikasinya. 2nd edn. Guna Widya. 2008: 5.

[4] Purnawi, Dewisetya. Penerapan Quality Function Deployment (QFD) Pada Unit Usaha di SMKN 2 Yogyakarta. Skripsi Universitas Negri Yogyakarta. 2013: 14.
[5] Sadikin Halim, Khawarita Siregar, Rosnani Ginting. Pendekatan Terpadu Menggunakan Metode Qfd-Anp Dalam Menentukan Sasaran Peningkatan Rancangan Pada Produk Springbed. eJurnal Teknik Industri FT USU Vol; 5, No. ss2. Maret 2014 pp. 1-5.

[6] Sunarso. Perancangan Troli Sebagai Alat Bantu Angkut Galon Air Mineral dengan Pendekatan Antropometri. Skripsi Universitas Sebelas Maret. 2010: 21.

[7] Tarwaka. Ergonomi Industri Dasar Dasar Pengetahuan Ergonomi Dan Aplikasi Di Tempat Kerja. II. Surakarta: Harapan Press. 2015: VII-340. 